1 Conning DM, Fletcher K, Swan AAB. Paraquat and related bipyridyls. Br Med Bull $1969 ; 25$ :245-9.

2 Connolly ME. Paraquat poisoning: clinical features. Proc $R$ Soc Med $1975 ; 68: 441$.

3 Fairshter RD, Wilson AF. Paraquat poisoning : manifestations and therapy. Am f Med 1975;59:751-3.

- Gardiner AJS. Pulmonary oedema in paraquat poisoning. Thorax 1972;27:132.

5airshter RD, Rosen SM, Smith WR, et al. Paraquat poisoning: new aspects of therapy. $Q \mathcal{F}$ Med 1976;45:551-65.

(Accepted 17 February 1982)

Wessex Renal Unit, Southampton University Department of Renal Medicine, Portsmouth PO3 6AD

L L NG, MA, MB, senior house officer

R B NAIK, MD, MRCP, lately senior registrar

A POLAK, MD, FRCP, profeseor of renal medicine

A POLAK, MD, ERe

\section{Response of thrombotic thrombocytopenic purpura to chlorpromazine}

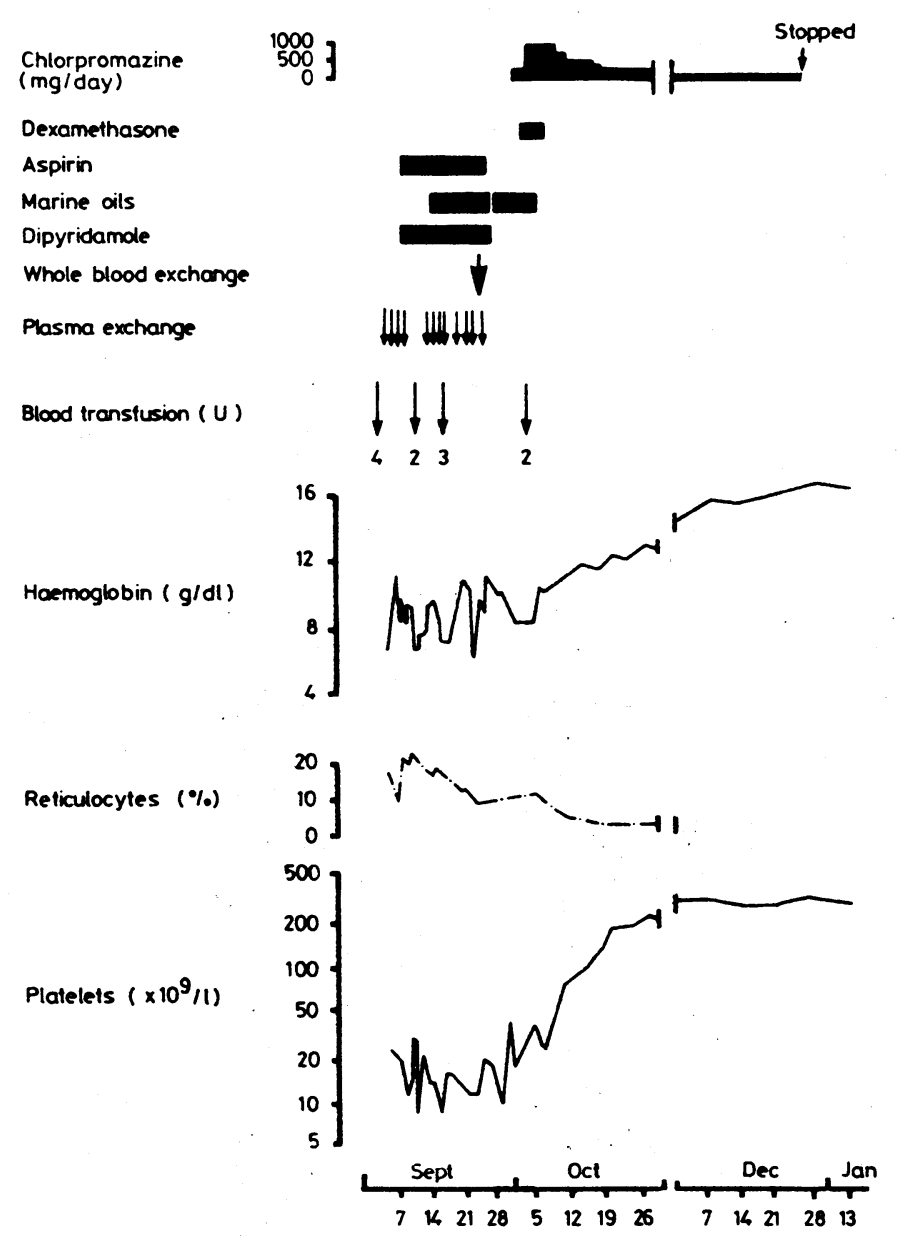

Thrombotic thrombocytopenic purpura is a rare disorder characterised by haemolytic anaemia, thrombocytopenia, neuropsychiatric disturbances, and hyaline arteriolar occlusions." It was previously associated with high mortality, ${ }^{2}$ but repeated plasma exchange has improved the prognosis. ${ }^{3}$ We describe a patient in whom chlorpromazine appeared to produce complete and sustained remission of the disease.

\section{Case report}

A 50-year-old industrial engineer had a two-month history of increasing lethargy, malaise, and anorexia and a two-week history of fever and painless haematuria. On admission to hospital he was confused and showed clinical anaemia, icterus, and a petechial rash. Haemoglobin concentration was $6.4 \mathrm{~g} / \mathrm{dl}$, platelet count $40 \times 10^{\circ} / 1$, and reticulocyte count $5 \%$ (figure). A blood film showed polychromasia, anisopoikilocytosis, microspherocytosis, and red-cell fragmentation. Coagulation studies were mildly abnormal, with prothrombin time $17.5 \mathrm{~s}$ (control $15 \mathrm{~s}$ ), activated partial thromboplastin time $48 \mathrm{~s}$ (control $35 \mathrm{~s}$ ), and thrombin time $28 \mathrm{~s}$ (control $25 \mathrm{~s}$ ) and the titre of fibrin and fibrinogen degradation products $1 / 16$ (normal $<1 / 8$ ). A direct Coombs test and Ham's test yielded negative results. Free haemoglobin was present in the urine. Bone-marrow cytology showed hyperplasia of all circulating cell precursors. Blood cultures showed no growth. Thrombotic thrombocytopenic purpura was diagnosed.

He rapidly became comatose with severe cerebral irritation. Intensive treatment by repeated plasma exchange produced considerable but temporary benefit with normal conscious level and slight but transient improvement in circulating platelet concentrations. Intermittent red-cell transfusions were required for anaemia. Two grand mal seizures were treated by intravenous diazepam, and prophylactic phenytoin was given. No clinical or haematological improvement followed treatment with dexamethasone, marine oils (Maxepa; British Cod Liver Oils, Hull), low-dose aspirin, or dipyridamole.

Six weeks after admission he again became confused and showed amnesia, paranoia, sexual disinhibition, and visual and persecutory auditory hallucinations. An acute organic confusional state was diagnosed and high-dose ( $1 \mathrm{~g}$ daily) chlorpromazine prescribed, with rapid and permanent improvement in his mental state. Serial blood counts showed a sustained improvement in haemoglobin concentration and platelet counts and a reciprocal diminution of reticulocytosis. After two weeks' treatment with chlorpromazine the platelet count became normal $\left(>150 \times 10^{\circ} / 1\right)$ and after a further four weeks the haemoglobin concentration was greater than $14 \mathrm{~g} / \mathrm{dl}$. The chlorpromazine was gradually withdrawn and relapse did not occur.

\section{Comment}

The start of a course of chlorpromazine corresponded in our patient with the onset of eventual total remission of thrombotic thrombocytopenic purpura. We believe that this represents a true response of this unpredictable disease to the drug but recognise that it might have been fortuitous and due to a spontaneous remission. We had no opportunity for re-evaluating the effect of chlorpromazine as our patient remained in complete remission. oral chlorpromazine and other treatment.

The pharmacological properties of chlorpromazine lend weight to our argument that this was a true drug-related response of the disease. Chlorpromazine is a cell-membrane stabiliser that is antihaemolytic in vitro at concentrations that are found therapeutically, and it also diminishes the haemolysis produced by shear stress at pressures similar to those found in arterioles. ${ }^{5}$ The hyaline arteriolar lesions of thrombotic thrombocytopenic purpura ${ }^{2}$ might represent the cause or effect of haemolysis at sites of high shear stress. Chlorpromazine may prevent haemolysis with its consequent liberation of adenosine diphosphate, which is a powerful platelet-aggregating agent. ${ }^{5}$ This might be the underlying mechanism of the thrombocytopenia. We suggest that chlorpromazine should be evaluated as soon as possible in further cases of thrombotic thrombocytopenic purpura.

1 Moschcowitz E. An acute febrile pleiochromic anaemia with hyaline thrombosis of the terminal arterioles and capillaries. Arch Intern Med $1925 ; 36: 89-93$.

2 Amorosi EL, Ultman JE. Thrombotic thrombocytopenic purpura: report of 16 cases and review of the literature. Medicine (Baltimore) 1966;45: 139-59.

${ }^{3}$ Bukowski RM, King JW, Hewlett JS. Plasmapheresis in the treatment of thrombotic thrombocytopenic purpura. Blood 1977;50:413-7.

- Seeman P. The membrane actions of anaesthetics and tranquillizers. Pharmacol Rev 1972;24:583-655.

5 Born GVR, Wehmeier A. Inhibition of platelet thrombus formation by chlorpromazine acting to diminish haemolysis. Nature $1979 ; 282: 212-3$.

(Accepted 17 February 1982) Infirmary, Manchester M13 9WL

R T WENSLEY, MRCP, MRCPATH, consultant haematologist

ANN C CUTHBERT, MB, CHB, research fellow
Time relation of changes in haematological variables to administration of

University Department of Clinical Haematology, Manchester Royal 